\section{7a OCCUPATION AND COPD}

David Fishwick. University of Sheffield, UK

10.1136/oemed-2018-ICOHabstracts.1302

Occupational exposures are able to cause a variety of occupational lung diseases that effect either predominantly the airway or the lung parenchyma. Exposures to agents at work that are able to cause COPD remain globally common, although the evidence supporting each of these is variable. Better evidence is available to support the roles of silica, grain dust, coal and cadmium, for example, as specific causes of occupational COPD, whilst multiple epidemiologic al studies also support the harmful effect of exposures to vapours, gases dusts and fumes.

This presentation will summarise the current view of occupational COPD, to include its definition, common causes and it will also include discussion of the uncertainties around occupational COPD. The talk will also include specific mention of the harmful effects of inhaled respiratory crystalline silica, and the continuing global problems associated with silicosis.

\section{7b OCCUPATION AND ASTHMA}

JR Feary. Royal Brompton Hospital, London, UK

10.1136/oemed-2018-ICOHabstracts. 1303

Asthma is widely recognised to be a heterogenous disease with several 'endotypes'; differentiation of these is not necessarily straightforward and requires assessment from several different angles. Moreover there is increasing evidence that the label is (over-) applied inappropriately.

The often close relationships between occupation and asthma are equally well recognised. Employees, for example, may develop a work-related exacerbation of their pre-existing disease or, de novo, 'occupational asthma', usually as a result of an acquired hypersensitivity to a, airborne, workplace sensitising agent; differentiation between these two conditions is often, but not always, straightforward.

However, not infrequently, respiratory symptoms are erroneously attributed to asthma when they are in fact, a reflection of other conditions originating in the upper airway or in relation to disordered breathing patterns. Correct identification of these conditions allows individuals to remain in their current job and avoids the use of protracted polypharmacy; novel approaches are available to assist in making these diagnoses and help to direct appropriate management.

In addition to assessment of current symptoms, a key question often posed is how an individual's asthma will affect their future employment? There is good evidence that variation between individuals is greater than that within an individual-;this allows the prediction of risk of future exacerbations and of the risks of recurrence of remitted childhood disease.

This presentation will review modern approaches to diagnosis and management of asthma and related conditions, including the appropriate role of novel, biologic, treatments.

\section{2 WORK-RELATED ASTHMA ASSOCIATED WITH HIGH PREVALENCE OF RESPIRATORY SYMPTOMS AND REDUCED WORK-ABILITY IN A CROSS-SECTIONAL POPULATION BASED STUDY FROM NORWAY}

${ }^{1,2}$ G Klepaker*, 'MV Svendsen, ${ }^{2,3}$ J Kongerud, ${ }^{1}$ AKM Fell. ${ }^{1}$ Department of Occupational and Environmental Medicine, Telemark Hospital, Skien, Norway; ${ }^{2}$ nstitute of Clinical Medicine, Faculty of Medicine, University of Oslo, Oslo, Norway; ${ }^{3}$ Department of Respiratory Medicine, Oslo University Hospital, Oslo, Norway

\subsection{6/oemed-2018-ICOHabstracts. 1304}

Introduction Some studies have indicated that patients with occupational asthma have more severe disease than other asthma patient. Indicators of severity may be reduced quality of life and higher levels of sick-leave and disability. There are, however, few studies assessing respiratory symptom prevalence and work-ability. The aim of our study was to estimate the differences in respiratory symptom prevalence and work-ability between patients with indication of work-related asthma compared with other asthma patients.

Methods The association between work-relation and respiratory symptoms and work ability was assed among 16099 subjects from the general population, aged 16 to 50 years, included in a cross-sectional study form Telemark, Norway. 828 subjects that reported having physician-diagnosed asthma, ever being employed and currently using asthma medication were included. Of these 171 (21\%) had respiratory symptoms at work that improved during weekends, holydays, other absence from work or change of work. These were compared with the remaining patients with physician-diagnosed asthma $(n=657)$. Self-reported work-ability was assessed by the first single item question of the work ability index (WAI). Analyses where adjusted for age, gender, education and occupational group.

Result The patients with work-related asthma reported significantly more respiratory symptoms in the past 12 months; wheezing (OR 2.6, 95\% CI: 1.5 to 4.5 ), woken by dyspnoea during the night (OR 2.0, 95\% CI: 1.4 to 2.8), woken by coughing (OR 1.8, 95\% CI: 1.3 to 2.6), asthma attack (OR 2.2, 95\% CI: 1.5 to 3.1 ) and reduced work-ability (OR 2.3, 95\% CI: 1.5 to 3.3 ).

Discussion Our study indicates that work-related asthma is associated with higher prevalence of respiratory symptoms and reduced work-ability (score $<8$ ) compared with asthma without work-relation. These findings support the hypothesis suggesting that occupational asthma may be more severe than non-occupational asthma.

\section{OCCUPATIONAL RESPIRATORY DISORDERS IN A CHEMICAL' INDUSTRY IN TOGO}

\footnotetext{
${ }^{1}$ Antoine Vikkey Hinson*, ${ }^{2}$ Gbéhomilo Edhorh, ${ }^{3}$ Koffi Atsu Aziagbe, ${ }^{4}$ Badirou Aguemon, ${ }^{5}$ Fabien Gounongbe, ${ }^{1}$ Menonli Adjobimey, 'Benjamin Fayomi. 'Unity of Teaching and Research in Occupational Health and Environment, Faculty of Sciences and Health of Cotonou (University of Abomey-Calavi Benin); ${ }^{2}$ Service des Urgences médicales du Centre Hospitalier Universitaire Sylvanus Olympio de Lomé-Togo; ${ }^{3}$ Senvice de Pneumo-phtisiologie du Centre Hospitalier Universitaire Sylvanus Olympio de Lomé-Togo; ${ }^{4}$ Département de Santé Publique, unité de biostatistique Faculté des Sciences de la Santé de Cotonou (Université d'Abomey-Calavi Bénin); ${ }^{5}$ Département de Médecine et Spécialités Médicales, Faculté de Médecine, Université de Parakou Bénin
}

10.1136/oemed-2018-ICOHabstracts. 1305 